\title{
Negotiating agency in cases of intimate partner violence in Vietnam
}

Kirrily Pells,,$^{{ }^{*}}$ Emma Wilson $^{\mathrm{b}}$ and Thi Thu Hang Nguyen ${ }^{\mathrm{c}}$

aYoung Lives, Oxford Department of International Development, University of Oxford, Oxford, UK.; 'baculty of Epidemiology and Population Health, London School of Hygiene and Tropical Medicine, London, UK.; 'Centre for Analysis and Forecasting, Vietnam Academy of Social Sciences, Hanoi, Vietnam

*Corresponding author. Email: kirrily.pells@qeh.ox.ac.uk 
Understandings of women's agency in cases of intimate partner violence (IPV) has been dominated by an individualistic focus on help-seeking behaviour. The role of children in influencing, enabling and restricting the decision-making processes of their mothers has been largely ignored. We adopt biographical analytical approaches to qualitative longitudinal data collected as part of the Young Lives study to highlight the interdependency of women's and children's agency in contexts of IPV in Vietnam. We illustrate how women's agency is both enabled and constrained by their relationships with their children, as well as by wider structural processes and examine how gender and generation intersect. In marginalised settings where few formal services exist or strong social norms preclude women from accessing support, understanding these informal coping strategies and the processes by which these are negotiated, is essential for developing more effective policy responses.

Keywords: intimate partner violence; agency; help-seeking behaviour; children; Vietnam 


\section{Introduction}

Global public health policy places high importance on strengthening the individual agency of women to negotiate intimate partner violence (IPV) while often neglecting how women's decisions are influenced, enabled, and potentially restricted by their children. ${ }^{1}$ Indeed, children have been largely overlooked as important mediators of IPV as much of the existing research portrays children as passive witnesses or victims of IPV, rather than social actors who are capable of developing their own responses and coping strategies (Overlien \& Hyden, 2009; Katz, 2015). This paper draws on qualitative longitudinal data collected with two cohorts of children (aged 9-10 and 1617 in 2011) and their mothers in Vietnam, to make two distinct contributions to understandings of women's agency in the context of IPV. Firstly, the paper moves beyond an individualistic framing of agency to highlight the interdependency of women's and children's decision-making. Women's agency is both enabled and constrained by their relationships with their children, as well as by wider structural inequalities, such as poverty and social norms. Secondly, agency takes multiple and sometimes contradictory forms, as women undertake varied strategies to respond to violence. Agency is therefore better understood as a dynamic and interdependent process where decisions are negotiated within interpersonal relationships and shaped by structural inequalities.

\section{An interdependent framework for understanding women's agency}

Within the literature on IPV, the social, cultural and interpersonal factors influencing women's help-seeking are widely recognised (Liang, Goodman, Tummala-Narra, \& Weintraub, 2005). Yet in both policy and practice, there is a risk that women may only be perceived to be 'agentic', and reframed as 'survivors' of violence, once they have reached a certain endpoint, such as disclosing the violence to a service provider 
(Paterson, 2010). This overlooks the 'processual' nature of agency, which places emphasis on the pathways by which people acquire the ability to make 'strategic life choices' (Kabeer, 1999, p. 437), as well as the multiplicity of women's resistance and resilience strategies, even in contexts where women do not actively seek support. As Coates and Wade (2007) suggest: 'Resistance is ubiquitous: Whenever individuals are subjected to violence, they resist' (p. 513).

Few women seek formal institutional support for IPV, particularly in contexts of poverty where services are often under-developed and women lack the necessary resources to do so (Liang et al., 2005). In Vietnam, a population-based survey found that a third of ever-married women had experienced physical violence, one in ten reported sexual violence and over half had endured emotional violence (General Statistics Office, 2010). However, $87 \%$ of women who reported IPV in the survey had never sought help from formal services or the authorities. The main reasons for this included fear of the shame and stigma associated with seeking support, as well as a belief that the violence was normal and not serious enough to warrant assistance.

This suggests the need for a broader framing of agency which takes account of the ways in which agency is both constrained, as well as the ways in which these constraints are negotiated in contexts of IPV. As a starting point we adopt Kabeer's (1999) conceptualisation of agency:

Agency is about more than observable action; it also encompasses the meaning, motivation and purpose which individuals bring to their activity [...] It can take the form of bargaining and negotiation, deception and manipulation, subversion and resistance as well as more intangible, cognitive processes of reflection and analysis (p. 438).

This more processual and dynamic framing of agency allows us to explore an underresearched area: how agency is negotiated between mothers and children and how this 
results in multiple and sometimes contradictory strategies. These strategies can range from moments of open defiance to more indirect strategies such as children financially supporting their mother (or vice versa) unbeknown to the father, which can both simultaneously subvert and reinforce the status quo.

\section{Negotiating agency at the intersections between gender and generation}

The relationships between mothers and children in contexts of IPV are poorly understood, particularly in the Global South. Children tend to be featured as passive victims in both policy and research. ${ }^{2}$ Research is dominated by the field of development psychology conducted primarily in the Global North, which highlights the adverse consequences of violence for individual children's physical, cognitive and emotional development (Carlson, 2000; Kitzmann, Gaylord, Holt \& Kenny, 2003).

In contrast, sociological approaches to childhood have sought to foreground the notion of children as agentive social actors rather than as 'passive subjects of social structures and processes' (Prout \& James, 1990, p. 8). Framed by this approach, research from the UK and Sweden with children ranging in age from 5 to 17 years old, has demonstrated that although most children are adversely affected by violence in the home, children also develop a range of coping strategies (McGee, 2000; Mullender et al., 2002; Overlien, 2010; Overlien \& Hyden, 2009). Strategies reported by children included: physical or emotional removal from the situation (such as pretending that the violence is not taking place); looking after, or being looked after, by siblings; building networks of social support; and finding ways to protect their mother, including intervening in the violence by fetching help (Mullender et al., 2002, pp. 124-30). While witnessing IPV may have differing effects on children according to their developmental stage, with younger children having less coping skills and 
resources (Carlson, 2000, p. 330) children do not remain passive in the face of violence, regardless of age (McGee, 2000, p. 110; Mullender et al. 2002, p. 239). Moreover, children's actions may influence the responses of those around them, especially their mothers (Katz, 2015). This is not to downplay the potentially damaging impact of IPV on children but rather to build a more comprehensive picture of children's experiences and responses to generate more effective policy responses.

However, in recent years, theorisations of agency, whether related to women or children or other marginalised groups, have been increasingly critiqued. Firstly, agency is often framed as an end in itself (Madhok, Phillips \& Wilson, 2013, p. 4). Instead there is a need to move beyond repeated assertions that children and youth [and equally women] have agency, to question what form this agency takes (Durham, 2008, p. 151) and to challenge simplistic binaries which position both women and children as either vulnerable or agentive (Bordonaro \& Payne, 2012; Madhok et al., 2013, p. 3; Pells, 2012).

Secondly, the assumption that agency is 'resourcefulness, resistance to hegemony and domination, and as something inherently positive' has been questioned. Agency may take more 'ambiguous' forms which can reinforce domination or seemingly go against self-interest (Bordonaro \& Payne, 2012, p. 367). In the context of IPV a few studies have documented how children's actions influence their mothers, yet this does not always results in positive outcomes (Katz, 2015) and more consideration is needed of the ways in which children's agency may reinforce the status quo or appear irrational (Valentine, 2011, pp. 351, 354).

The similarities between the critiques of the dominant constructions of agency emerging both within feminist and childhood research suggest the need for a 
conceptual lens, which takes better account of both agency as a process, which takes multiple and sometimes ambiguous forms as well as the ways in which it is negotiated between men and women, adults and children and the structural forces which shape these interactions (Alanen, 1994; Oakley, 1994). In this paper we seek to understand how the interrelationships between gender and generation structure experiences and responses to IPV in the context of broader structural inequalities, such as poverty, discriminatory social norms and limited access to services. In doing so, we draw on Bourdieu's (2000) concept of the habitus, defined as:

...a set of dispositions, reflexes and terms of behaviour people acquire through acting in society. It reflects the different positions people have in society, for example whether they are brought up in a middle class environment or in a working class suburb. It is part of how society reproduces itself (p. 18).

Thus structural inequalities not only shape the habitus, but are also reproduced through the daily interactions and embodiment within the habitus (Reay 2004, p. 436). Violence can be reproduced as the actions of the dominator can become embodied by the dominated through the daily interactions and perceptions of the habitus (Bourdieu, 1977, p. 97). As we will see women and children may adopt strategies which appear to reinforce rather than challenge the status quo. Yet this is not 'mechanical determinism,' devoid of choice and opportunity, but rather 'invention within limits.' Individuals have a scope for creativity but this is constrained and determined by a series of 'orientations and limits' within the habitus, in particular the persistence of strong gender norms (Bourdieu, 1977, pp. 95).

Drawing on this framing, we explore how the agency of women and children and the interactions between them, can therefore reproduce and challenge dominant structures and social norms (Reay, 2004, pp. 434-5; Valentine, 2011, p. 355). In the following section we examine some of these different structures and social norms 
which shape the daily interactions and relationships of men, women and children and their responses to IPV in Vietnam.

\section{Agency and competing gender ideologies in Vietnam}

Vietnam has made great strides in reducing gender gaps in education, health and employment and ranks 58 out of 148 countries on the United Nations Development Programme (UNDP) Gender Inequality Index. ${ }^{3}$ Gender equality has been promoted in both legislation and policy and the 2007 Domestic Violence Control and Prevention Law adopts a broad definition of domestic violence as encompassing 'purposeful acts of certain family members that cause or may possibly cause physical, mental or economic injuries to other family members. ${ }^{4}$ However, in practice there exists a 'blending of egalitarian and inegalitarian gender norms' which place competing pressures and obligations on women (Santillan, Schuler, Haong, Trang, \& Bui, 2002).

The simultaneous promotion and constraining of the role and agency of women is seen most clearly in the activities of the Vietnam Women's Union (VWU) which is the largest women's organisation in Vietnam, and the main conduit for the implementation of state-led policies on gender equality and family policy, particularly at the community level (Waibel \& Gluck, 2013). The VWU regularly conducts national campaigns to mobilise women in their roles as both mothers and workers, which serve to conflate the interests of the nation with those of the family. For example, the 'Three Criteria' campaign encouraged women to 'study actively, work creatively, raise children well and build happy families' and utilised a set of indicators (such as children's performance in school) to measure women's achievements (Schuler et al., 2006, p. 385). Women are therefore placed under enormous pressures, 
to be not only economically astute and productive, but also to be self-sacrificing and prioritise familial harmony above all else (Schuler et al., 2006, p. 391).

The concept of family harmony is rooted in older Taoist and Confucian philosophical traditions. Taoism constructs the opposing forces of 'cool' female ideals of gentleness and sweetness, and 'hot' male ideals of physical strength and hot temper which together are seen to generate a sense of 'harmony' between male and female bodies and interactions (Rydstrom, 2004). An idealised vision of womanhood is promoted by Confucianism, based on the four feminine virtues of 'housework (cong), appearance (dung), speech (ngon) and conduct (hanh)' (Ngo, 2004, p. 50). To achieve these virtues, women traditionally were confined primarily to the private sphere and to the service of the family. Women were required to follow the moral code of the 'three obediences': 'at home she follows her father, married she follows her husband, widowed she follows her son' (Nguyen, 1995 cited in Volkmann, 2005, p. 26).

Such conceptualisations, together with public discourses surrounding women's contemporary social roles, place an overwhelming responsibility on women to 'endure' in order to maintain the semblance of 'harmony' within the home, for the good of both the nation and the family (Rydstrom, 2003; Schuler et al., 2006). Women continue to bear responsibility for 'raising children well' while also maintaining 'good relationships with their parents' (Schuler et al., 2006, p. 386). Thus understanding women's agency in these settings necessitates both a gender and generational lens to understand the structural and social constraints that influence and shape women's actions and decisions.

\section{Methods}


Our analysis is based on qualitative longitudinal data from the Young Lives study generated with families living in contexts of poverty in Vietnam. ${ }^{5}$ The qualitative component consists of a nested sample of 47 children from two cohorts (an older cohort born in 1994-5, and 25 from a younger cohort born in 2001-2) together with their caregivers (mostly mothers). This complements the household and child-level surveys, which are conducted every 3 years, with a wider sample of 1000 older cohort and 2000 younger cohort children.

In the first stage of our analysis we conducted a preliminary surface level reading of interview data generated with 47 children (23 girls and 24 boys) and their mothers (in some cases, their fathers as well) in 2007 and 2011. From this analysis we identified 12 cases of women and their children who described experiences of domestic violence (principally perpetrated by the child's father against their mother, but on occasions also involving violence on the part of step-fathers or the father's/step-father's male and female relatives against the child's mother). From these 12 , we selected 5 cases of IPV perpetrated by the child's father against his or her mother, to analyse in greater depth by adopting a case-level biographical approach. These were chosen purposively (each case consisting of a child and their mother) as illustrative (rather than representative) examples of the different ways in which agency is negotiated between children and mothers experiencing IPV within our study sites in Vietnam. All the children and mothers have been assigned pseudonyms.

The qualitative data are drawn from 3 sites- Van Lam, Van Tri and Nghia Tan (also pseudonyms) - which were purposively selected from the 20 survey research sites to capture variation in location, ethnicity (Kinh and minority ethnic groups) and social and economic circumstances (see Crivello, Morrow \& Wilson, 2013). Van 
Lam is a very poor mountainous community in the South-Central coast of Vietnam populated by many ethnic minority groups (mostly Cham H'roi); Van Tri is a prosperous rural area in the Red River Delta, with a high population density and good infrastructure; while Nghia Tan is an urban neighbourhood in Da Nang city, with average infrastructure where people are engaged mostly in manual labour.

Fieldworkers typically spent 2-3 days living with each family. During this time they used a variety of research methods including talk-based methods such as semi-structured interviews, observational methods, as well as creative and interactive techniques such as drawings and community walks (see Crivello et al., 2013). Group discussions were also held with community representatives such as teachers, local politicians and health workers.

Wherever possible, children and caregivers were interviewed separately, usually in their home or in a setting in the surrounding locality. Fieldworkers endeavoured to ensure that interviews were conducted in private. However this was not always possible or feasible, and inevitably some discussions may have been interrupted by other family members, thus influencing the reporting of violence (Morrow \& Singh, 2014).

Furthermore children and mothers were not asked explicitly about their experiences of violence as Young Lives is not a dedicated study of violence. Rather, this theme was raised by participants during discussions of family and community life, perceptions of well-being and within mothers' life history narratives. Fieldworkers are trained in the principles and standards set by Save the Children's (2003) 'Child Protection Policy'. Serious cases of abuse and exploitation are referred to relevant authorities and service providers, or, where these do not exist, local teams 
may investigate informal support networks available to children and women (Morrow, 2009).

\section{Women's agency in contexts of IPV}

In this section we explore how women's agency in the face of IPV is shaped by structural constraints and gender norms. While some women adopt direct strategies to confront their husbands, more often women develop multiple, indirect strategies through their everyday activities, in particular to protect their children's well-being.

Considerable variation exists across Vietnam in the availability of formal services and support for women experiencing IPV. In our research, the introduction of a programme to tackle domestic violence in 2007 was identified within community focus group discussions in urban Nghia Tan as one of the most important events affecting residents in recent years. Both men and women $(n=12)$ in the group discussions reported positive changes following the implementation of the locally-led programme, which included training for local officials, a sensitization campaign and the establishment of a helpline run by the Women's Union:

After the Combating Domestic Violence Program was implemented, there have been clear changes in the locality. For example, before, people wouldn't go to jail for domestic violence, but now they do. People got better after the education and training (female, age 47, Nghia Tan).

This is in stark contrast to the community discussions in rural Van Lam where IPV appeared to be more normalised. Here violence in the home (including IPV) featured much lower in adults' indicators of good and bad life for children. In one group discussion, the men asked for one of the 'bad' life indicators proposed by the group ('having a drunk father who usually beats the mother') to be removed at the end of the discussion as they explained that this was common behaviour. 
Despite the variation in societal attitudes and norms surrounding IPV, none of the women in any of the three communities who spoke of experiencing violence in the home had accessed formal support services. Instead they described informal strategies, ranging from openly challenging their husbands to resisting in multiple ways through their everyday actions.

Kim (age 58, Nghia Tan), who has five children and works as a fish grinder in the local market, first experienced physical violence while working as a domestic servant at the age of ten. As she grew older, she saw marriage as an opportunity to escape the violence. Yet soon after her union, she began to experience systematic physical and emotional abuse from both her husband and his family (mother and sisters). After only one year of marriage she attempted to leave her husband and tore up her marriage certificate in an open act of defiance. However, Kim soon found that her options were limited as she was unable to rely on her own family for fear of contravening filial piety:

He [her husband] beat me ruthlessly. At that time we had the first son already, I was beaten too much so I couldn't stand it, and I tore the marriage certificate. [...] then I left his home, but I didn't dare to go home to my village. The villagers would say, "you were sent to your husband's house, you got married, so why are you here, you might have been too bad and driven away by your husband"; it would make my father angry. [...] I went to another place. I rented a house to live. As his family drove me away, so I had to rent a house. Then I didn't have money for renting, I went to the market and slept there.

Kim later returned to live with her husband and resigned herself to 'endure' her circumstances in silence rather than risk bringing any possible shame on her family, even though exit strategies such as divorce have become more commonplace than in the past:

I was afraid of villagers thinking badly of my father, so I decided to endure in silence by myself. In the past, in my village, people considered 
a good lady as the one who had only one husband but not two. But now, if you don't like your husband, you can divorce him, and get married again to the second man, but in the past, there was no divorce at all. But I avoided a bad reputation for my parents as I didn't want to be undutiful to my parents as well. Now if I divorce my husband, I would bring a bad reputation to my parents, therefore I have to endure in silence by myself. And I also felt sorry for my poor children.

Kim's narrative illustrates how women's options for leaving relationships are constrained by intersecting structural disadvantages, such as poverty and social norms that emphasize filial piety and constructs of harmonious families. Yet it also suggests that these structural disadvantages are in flux, as women in contemporary society are perceived to have increased opportunities for divorce than previous generations (although this was still not viewed as a viable option by Kim).

Like Kim, other women narrated how on occasions they confronted their husbands' behaviour directly. However, this invariably led to an escalation of violence. Khanh (age 54, Nghia Tan) described talking back when her husband verbally abused her, 'He gets really mad when I talk back. I talk back, and then we go back and forth and it becomes a big deal'. When Bich (age 45, Van Tri) questioned her husband's financial neglect of the family, this was met with a violent response:

He took money [...] the money we used to pay the wages of the construction workers. My God! I asked him in a very gentle way about where he had put the money so I could take it back. He got angry with me and said "what's wrong if I keep the money? Am I wasting too much money?" I just told him that his money is mine and my money is his because we are husband and wife... however he just swore at me and started to beat me. I was so upset I intended not to go to work the next day; however I eventually went to work because I knew I needed to earn money in order to pay wages to our construction workers.

Although unable to escape the violence, it is clear that these women are far from 'passive' and devoid of agency. Instead they have resisted indirectly by determining and achieving their own goals, within the constraints of their lived realities, thus bringing 'meaning, motivation and purpose... to their activity' (Kabeer, 
1999, p. 438). As in other settings (see for example Parson, 2010) the women described their resolve and determination to ensure the household's survival and to secure opportunities for their children, in terms of education, work and marriage. This was illustrated by Bich:

Sometimes I think life is too bad but I still need to be smiling and keep working. Since working provides me with money I have saved to help my children when they need it to apply for jobs. I have to save money. That's it....

...I just told my children that there will be no more rice fields for them to cultivate in the future...they should try to study. I told Lien [her daughter] to apply and take the entrance exam to a university or college that has a good chance of getting her a job after graduation.

Kim was also determined to ensure that her children have a better life than she did. She had little social and economic support from her immediate family and she put herself under considerable financial pressure by taking a number of loans from the Women's Union to enable her sons to go to school. One son finished grade 10 and another was accepted into university. These achievements have been a source of enormous pride for her as she herself was never educated. Her efforts were also publically recognised in her community:

...when my son passed the entrance exams to the university, the whole community voluntarily collected money to buy a motorbike for him costing 4.5 million Vietnamese dong.... They said, "the children are from a poor family, but they were good at school." They were all happy for him. They said, "the mother was very hard working, but her children were all good at school."

These actions might be construed as women's 'willing participation' in their own subjugation (Paterson, 2010), by adding to their work burden, and further entrenching women's value in maintaining family harmony and traditional gender roles of caregiving and nurturing. Indeed women's strategies and choices are inevitably shaped and constrained by the 'objective' social structures, within which they are situated thus allowing for the reproduction of dominant social norms 
(Bourdieu, 2000, p. 19). At the same time this is not always the case, as Kim's and Bich's momentary acts of open defiance demonstrated. Furthermore, it is important not to sweep aside the potential fortitude and meaning that abused women may garner from these more indirect strategies or 'ambiguous' forms of agency, by which they continue to provide for their family, and secure their children's prospects, under very difficult conditions.

\section{Children's agency in the context of IPV}

The habitus of children, like that of their mothers is shaped (albeit in different ways) both by broader structural disadvantage and differential access to resources and networks. Consequently, children's responses to violence are multiple and varied, influenced by age, gender, economic resources and social networks, as well as the nature of the violence experienced (Mullender et al., 2002; See also Pells, Wilson \& Nguyen, in press).

In our case studies, the strategies of the younger children (aged 9 and 10) centred on physically avoiding episodes of violence by hiding or going to a relative's home. Older children, also described adopting indirect strategies, but focusing on distancing themselves emotionally. At the time of her last interview, Lien was aged 17 years and living in Van Tri. Her father had an affair and physically beat her mother (Bich), when Lien was a young girl. Lien suggested that she preferred not to discuss the situation openly with other family members and despite being visibly upset in the interview she explained 'I do not bother myself about family problems...I just let it be'. While such indirect strategies may not be beneficial to children's wellbeing in the longer-term, in the short-term they can have a protective role in preventing children from being overwhelmed (Mullender et al., 2002, p. 119). 
Other accounts illustrate how older children may intervene directly. Lam aged 11, who was living in Nghia Tan, spoke of instances when her brother, who is 2 years older than her, tried to intervene to stop her father from hitting her mother. When her father was throwing things at her mother, she described how her brother 'holds the big [bread] basket' and 'he says "stop, Dad."'

As children get older they can acquire more individual resources and more developed social networks, which enable them to influence familial dynamics and interactions within the home. These resources may be employed not only to further their own well-being but also to protect and support their mothers, although children's supportive actions may not always be recognised and acknowledged as such. This is illustrated by the case of Quang.

Quang had just turned 18 when last interviewed in 2011 and was living in Nghia Tan. When probed on his memories of childhood, Quang identified the event he remembered the most as 'playing with mum and dad, feeling close and loved.' His parents separated in 2006 and divorced in 2008. Despite the emotional violence which preceded his parents' break up, whereby his father had an affair and then filed for divorce without his wife's knowledge, for Quang his parents' divorce is worse: 'now that they're divorced, it's not like in the past. I no longer have both parents like other people, this makes me sad.'

Quang has tried to protect his mother by hiding his feelings from her. Quang was age 15 when the divorce case was heard. He was asked to declare with whom he wished to live. As his younger brother wanted to reside with his mother, Quang opted to stay with his father: 'Because if I lived with my mother, would she have enough money? I wanted to live with my father to give her less problems.' Yet Quang's 
mother was unaware of her son's attempts to protect her and described him as 'cold, anything is fine. As long as someone provided for his education, he'd accept the situation.' In the end, his father left the locality to live in Sai Gon, and so Quang now lives with his mother and his father sends monthly financial support.

Older children also described indirect strategies to try and protect their mothers, drawing on social and economic resources (cf. Katz, 2015). For example, Nga is the second oldest of six siblings and was living in Nghia Tan. Nga decided to work to help her family after failing the exam required to progress to higher secondary school at age 15 . Nga explained that when the family were facing financial problems her father became violent, adding that he was frequently drunk. Nga described protecting her mother by staying up late and going to collect her father from the bar: 'I go wake him up and tell him to come home.' In this way she protected her mother by being the one to let her father back into the house when he was drunk. Nga also worked at her mother's café and gave her earnings to her mother. Nga was able to draw on social support from her peers: 'A few good friends who had to quit school because of their family situation' and who lent each other money. She also had a boyfriend and commented: 'we tell each other everything, sad and happy things.'

These narratives demonstrate how children are capable of making their own decisions and developing direct and indirect strategies in response to violence, which are shaped by varied, and intersecting, structural and social factors. Importantly, we have seen how, due to their social positioning, children may have access to different sets of resources than their mothers, which in turn can be utilised to alter the dynamics of violence and influence their mother's actions.

\section{Negotiating agency between generations}


In situations of IPV, both mothers and children often attempt to protect each other (Katz, 2015; McGee, 2000; Mullender, 2002). We have seen how both mothers and children adopt direct and indirect strategies, drawing on the different social, material and emotional resources at their disposal. Within this section we explore further how agency in responding to IPV is often negotiated between mothers and children and the 'mutual dependence and interdependence' that exists between generations.

Lien, age 17, daughter of Bich, described having limited emotional and social support as she 'seldom confides' in either her sister and is 'not so close' to her mother. Unlike Nga discussed in the previous section, Lien does not have a strong network of friends. In the absence of any other obvious option, the most attainable strategy for Lien was one of acceptance and encouraging her mother to do likewise. According to her mother Lien encouraged her to accept 'her fate' and told her to 'let it be' whenever she was visibly upset: '[Lien tells me] it is my fate; I don't need to tell anybody about it because even if I tell others, they cannot help me.' Her father is also complicit in this strategy; although he expressed regret, he too legitimised the status quo by claiming that he has no control over his actions: 'I still love my wife; however, it is our fate. $[\ldots]$ I don't know why I turn out like this.'

However, Bich would prefer to take a more active stance by bringing her very private suffering into a public forum. But she found herself impeded not only by her loyalty to Lien but also by the social and cultural taboos associated with family disunity that are engrained within the local context:

To be honest, there were times I really wanted to say everything out loud but she [Lien] prevented me from doing so.

(and later) 
I think many people know; however I don't want to tell them my story. Sometimes I tried to pretend there was no problem in our family so as to live a happy life. I don't talk much about it. It isn't something good to talk about.'

Everyday actions can therefore challenge, or in this case reproduce, the status quo. Accounts such as those of Lien and Bich reflect Bourdieu's (2004) conception of symbolic violence and the ways in which the 'dominated, often unwittingly, sometimes unwillingly, contribute to their own domination by tacitly accepting the limits imposed' (p. 341). Yet crucially this is as a result of 'objective structures,' such as strong social norms, shaping the subjective or habitus. Moreover, in the case of Lien we see how children are subject to the same social norms and can act as mediators of symbolic violence, by reinforcing traditional gender ideologies. Thus, children can co-construct their mothers' responses, in this case to maintain the appearance of familial harmony (Rydstrom, 2003; Schuler et al., 2006).

However, in other cases we see children wanting to take action but being dissuaded by their mothers. Kim was careful to hide the signs of violence from her own father, and explained how she was anxious not to burden her sons:

Now, my sons usually ask me what hurts you, or why you are sad or what makes you unhappy, please tell us all, don't hide from us, we can help you to solve your problems. I told them I have nothing to tell and nothing to share with them, I am happy now and I am not sad. Now I have nothing to share with them, I never expose my sad story to any of my sons.

She also related how in the past she intervened to prevent them from openly confronting her husband's family:

My eldest son...called his brothers and asked them to take care of me, he told them "You can fight against them" - my husband's brothers and sisters - "if they insult our mother even verbally." But I told my children not to insult them. I told my sons "If you insult them by saying bad things behind them, they will hurt your mother." 
In contrast to Lien, Kim's sons and Lam's brother, who challenged their father's violent behaviour appear to be subverting rather than reproducing established gender hierarchies. Traditionally, male elders in Vietnamese society are entitled to command respect from, and exert privilege over, younger male relatives due to their closer links to their patrilineal ancestry (Horton and Rydstrom, 2011, p. 548). However, such challenges to the established gender order can simultaneously be viewed as attempts by boys and young men to assume the role of protector within the family (a responsibility waived and abused by their fathers) while at the same time reinforcing masculine roles based on traits of strength and control.

While other studies have demonstrated that children factor in to a mother's decision-making in IPV cases (Rhodes, Cerulli, Dichter, Kothari, \& Barg, 2010) here we have suggested that children can play a far more active and influential role. The cases of Kim and Bich illustrate the mutuality of women and children in their responses to IPV, as both mothers have been acutely aware of how their actions may impact their children. How children, such as Kim's son, negotiate and mediate their responses is also dependent on the positioning and strategies adopted by their mothers. In this way, children's and mother's agency can intersect to co-construct responses to IPV, shaped by the power relations of gender and generation.

\section{Conclusion}

Within public health policy, women's agency in cases of IPV is often framed in individualistic terms in relation to help-seeking behaviour. This paper has sought to address some of the key shortcomings of dominant framings of women's and children's agency by adopting a conceptual lens which emphasizes both the dynamic nature of agency and the intersections between gender and generation. Our empirical 
evidence has demonstrated how women's habitus is shaped both by wider structural inequalities and limited access to services, as well as through interdependent relationships with their children. Women and children adopt multiple responses to violence, which are sometimes contradictory. Yet even where violence is not openly challenged, we have shown that both women and children do find opportunities to pursue agentic strategies, often indirectly.

Our findings provide further evidence of the processes and dynamics underlying women's help-seeking behaviour in the Global South and offer a series of implications for public health policy. Firstly, as in the case of Vietnam, the majority of women experiencing IPV do not access formal services and rely instead on informal sources of support, which often includes their children. Better understandings of how children experience and respond to IPV and how children influence their mothers' responses challenges policies and programmes which tend to conflate women's and children's needs, without recognising how these may be different (Mullender et al., 2002). Secondly, broader structural disadvantages, including poverty, limited access to services and social norms relating to the role of women in preserving family harmony shape women and children's experiences of and responses to IPV. Consequently, tackling IPV requires a series of interventions that work collectively to address these structural barriers that both put families at greater risk of experiencing violence, as well as constraining the agency of women and children and the processes by which agency is negotiated.

\section{Acknowledgements}

This work was supported by UK aid from the Department for International Development (DFID) from 2001 to 2017 under Grant number PO 5126 and by the Netherlands Ministry of Foreign Affairs under Grant number 20907.

We wish to thank the children and families participating in the Young Lives study for generously giving their time and sharing their experiences with us. We would also like to 
thank the team of researchers in Vietnam lead by Vu Thi Thanh Huong. Helpful comments were received on earlier versions of the paper from Gina Crivello, Virginia Morrow and our two anonymous reviewers.

\section{Disclosure Statement}

The authors have no conflicts of interest to declare.

\section{Notes}

1. We adopt the World Health Organisation's (2013) definition of IPV as 'behaviour by an intimate partner or ex-partner that causes physical, sexual or psychological harm, including physical aggression, sexual coercion, psychological abuse and controlling behaviours.'

2. In this paper 'children' refers to all individuals aged below 18 , as defined by the United Nations Convention on the Rights of the Child.

3. One is the country with the least gender inequality (UNDP, 2014, p. 174).

4. The law covers such acts as physical punishment, emotional violence (insults, isolating or shunning behaviour etc.), sexual violence (forced sex), economic abuses (including destruction of property, forced overwork or control of income to induce financial dependence) and covers married couples, divorcees and unmarried couples living together (National Assembly of Vietnam, 2007).

5. Young Lives is an international longitudinal study of childhood poverty which conducts large scale household and child surveys with 12,000 children and their primary caregivers in 4 countries - Peru, Ethiopia, India (Andhra Pradesh) and Vietnam (Crivello et al., 2013).

\section{References}

Alanen, L. (1994). Gender and generation: Feminism and the 'child question.' In J. Qvortrup, G. Sgritta \& H. Wintersberger (Eds.), Childhood matters: Social theory, practice and politics (pp. 27-42). Aldershot: Avebury.

Bordonaro, L. \& Payne, R. (2012). Ambiguous agency: Critical perspectives in social interventions with children and youth in Africa. Children's Geographies, 10(4), 365-372. doi: 10.1080/14733285.2012.726065

Bourdieu, P. (1977). Outline of a Theory of Practice. Cambridge: University of Cambridge.

Bourdieu, P. (2000). The politics of protest. An interview. Socialist Review, 242. Retrieved from http://pubs.socialistreviewindex.org.uk/sr242/ovenden.htm

Bourdieu, P. (2004). Gender and Symbolic Violence. In N. Scheper-Hughes \& P. Bourgois (Eds.), Violence in War and Peace: An Anthology (pp. 339-342). Oxford: Blackwell.

Carlson, B.E. (2000). Children exposed to intimate partner violence: Research findings and implications for intervention. Trauma, Violence and Abuse 1(4), 321-42. doi: 10.1177/1524838000001004002 
Coates, L. \& Wade, A. (2007). Language and violence: Analysis of four discursive operations. Journal of Family Violence, 22(7), 511-522. doi: 10.1007/s10896007-9082-2

Crivello, G., Morrow, V. \& Wilson, E. (2013). Young Lives longitudinal qualitative research: A guide for researchers. Technical Note 26, Oxford: Young Lives.

Drummond, L. \& Rydstrom, H. (2004). Introduction. In L. Drummond \& H. Rydstrom (Eds.), Gender Practices in Contemporary Vietnam (pp. 1-25). Copenhagen: NIAS.

Durham, D. (2008). Apathy and agency. The romance of agency and youth in Botswana. In J. Cole \& D. Durham (Eds.), Figuring the Future. Globalization and the temporalities of children and youth (pp. 151-178). Santa Fé: School for Advanced Research Press.

General Statistics Office (2010). 'Keeping silent is dying': Results from the National Study on Domestic Violence against Women in Viet Nam. Hanoi: GSO.

Horton, P. \& Rydstrom, H. (2011). Heterosexual masculinity in contemporary Vietnam: Privileges, pleasures and protests. Men and Masculinities 14(5), 542-564. doi: 10.1177/1097184X11409362

Kabeer, N. (1999). Resources, agency, achievements: Reflections on the measurement of women's empowerment. Development and Change, 30(3), 435-464. doi: $10.1111 / 1467-7660.00125$

Katz, E. (2015). Domestic violence, children's agency and mother-child relationships: Towards a more advanced model. Children and Society, 29(1), 69-79. doi: $10.1111 /$ chso. 12023

Kitzmann, K. M., Gaylord, N. K., Holt, A. R., \& Kenny, E.D. (2003). Child witnesses to domestic violence: A meta-analytic review. Journal of Consulting and Clinical Psychology, 71(2), 339-52. doi: 10.1037/0022-006X.71.2.339

Liang, B., Goodman, L., Tummala-Narra, P., \& Weintraub, S. (2005). A theoretical framework for understanding help-seeking processes among survivors of intimate partner violence. American Journal of Community Psychology, 36(1/2), 71-84. doi: 10.1007/s10464-005-6233-6

Madhok, S., Phillips, A., \& Wilson, K. (Eds). (2013). Gender, agency and coercion. Palgrave Macmillan: Basingstoke.

Mayall, B. (2002). Towards a sociology of childhood. Buckingham: Open Press.

McGee, C. (2000). Childhood experiences of domestic violence. London: Jessica Kingsley.

Morrow, V. (2009). The ethics of social research with children and families in Young Lives: Practical experiences. Working Paper 53, Oxford: Young Lives.

Morrow, V. \& R. Singh (2014). Corporal punishment in schools in Andhra Pradesh, India: Children's and parents' views. Working Paper 123, Oxford: Young Lives. 
Mullender, A., Hague, G., Imam, U., Kelly, L., Malos, E., \& Regan, L. (2002). Children's perspectives on domestic violence. London: SAGE.

National Assembly of Vietnam (2007). Law on Domestic Violence Prevention and Control, Law No.: 02/2007/QH12 Hanoi: National Assembly of Vietnam

Ngo, T.N.B. (2004). The Confucian four feminine virtues (tu duc): The old versus the new - ke thua Versus phat huy. In L. Drummond \& H. Rydstrom (Eds.), Gender Practices in Contemporary Vietnam (pp. 47-73). Copenhagen: NIAS.

Oakley, A. (1994). 'Women and children first and last: Parallels and differences between children's and women's studies.' In B. Mayall (Ed.), Children's Childhoods: Observed and Experienced (pp. 13-32). London: Falmer Press.

Overlien, C. (2010). Children exposed to domestic violence: Conclusions from the literature and challenges ahead. Journal of Social Work, 10(1), 80-97. doi: $10.1177 / 1468017309350663$

Overlien, C. \& Hyden, M. (2009). Children's actions when experiencing domestic violence. Childhood, 16(4), 479-496. doi: 10.1177/0907568209343757

Parson, N. (2010). “I am not [just] a rabbit who has a bunch of children!”: Agency in the midst of suffering at the intersections of global inequalities, gendered violence, and migration. Violence Against Women, 16(8), 881-901. doi: $10.1177 / 1077801210376224$

Paterson, S. (2010) 'Resistors,' 'Helpless Victims,' and 'Willing Participants': The Construction of Women's Resistance in Canadian Anti-Violence Policy. Social Politics 17(2), 159-184. doi:10.1093/sp/jxq001

Pells, K., Wilson, E. \& Nguyen, T.T.H. (in press). Gender violence in the home and childhoods in Vietnam. In J. Parkes (Ed.), Gender Violence in Poverty Contexts: The Educational Challenge. London: Routledge.

Prout, A. \& James, A. (1990). A new paradigm for the sociology of childhood? Provenance, promise and problems. In A. James \& A. Prout (Eds.). Constructing and Re-constructing Childhood (pp. 7-32). Basingstoke: Falmer Press.

Reay, D. (2004). 'It's all becoming a habitus': Beyond the habitual use of habitus in educational research. British Journal of Sociology of Education, 25(4), 431444. doi: 10.1080/0142569042000236934

Rhodes, K.V., Cerulli, C., Dichter, M.E., Kothari, C.L. \& Barg, F.K. (2010). “I didn't want to put them through that": The influence of children on victim decisionmaking in intimate partner violence cases. Journal of Family Violence, 25(5), 485-493, doi: 10.1007/s10896-010-9310-z

Rydstrom, H. (2003). Encountering 'hot' anger: Domestic violence in contemporary Vietnam. Violence Against Women, 9(6), 676-697. doi: $10.1177 / 1077801203009006004$

Rydstrom, H. (2004). Female and male 'characters': Images of identification and selfidentification for rural Vietnamese children and adolescents. In L. Drummond 
\& H. Rydstrom (Eds.), Gender Practices in Contemporary Vietnam (pp. 7495). Copenhagen: NIAS.

Santillan, D., Schuler, S., Hoang, T.A., Trang, H.M., \& Bui T.T.M (2002). Limited equality: Contradictory ideas about gender and the implication for reproductive health in rural Vietnam. Journal of Health Management, 4(2), 251-267. doi: 10.1177/097206340200400210

Save the Children (2003). Child protection policy. London: Save the Children Alliance.

Schuler, S.R., Hoang, T.A., Vu, S.H., Tran, H.M., Bui, T.T.M. \& Pham, V.T. (2006). Constructions of gender in Vietnam: In pursuit of the 'Three Criteria'. Culture, Health and Sexuality, 8(5), 383-394. doi:10.1080/13691050600887949

United Nations Development Programme (2014). Human Development Report 2014: Sustaining Human Progress: Reducing Vulnerabilities and Building Resilience. New York: UNDP.

Valentine, K. (2011). Accounting for Agency. Children and Society, 25(5), 347-358. doi: $10.1111 / j .1099-0860.2009 .00279 . x$

Volkmann, C.S. (2005). 30 years after the war: Children, families, and rights in Vietnam. International Journal of Law, Policy and the Family, 19(1), 23-46. doi: 10.1093/lawfam/ebi002

Waibel, G. \& Glück, S. (2013). More than 13 million: Mass mobilisation and gender politics in the Vietnam Women's Union. Gender and Development, 21(2), 343-361. doi: 10.1080/13552074.2013.802148

World Health Organization (2013). Violence against women: Intimate partner and sexual violence against women. Fact Sheet No. 239. Geneva: World Health Organization. from http://www.who.int/mediacentre/factsheets/fs239/en/ 